\title{
Solidarity in Europe: from crisis to policy?
}

\author{
Irina Ciornei ${ }^{1} \cdot$ Malcolm G. Ross $^{2}$
}

Published online: 18 February 2021

(c) Springer Nature Limited 2021

The European Union's recent history has been marked by various events that show Member States' uneasiness in finding a compromise between what the Union requires to maintain or deepen integration, on the one hand, and national interests, on the other. The economic and sovereign debt crises of 2008-2012, the asylum seeker crisis in 2015 and the Covid-19 pandemic, which, at the time of writing is still at its peak in Europe, illustrate the dialectic between the transnational outreach of environmental, social and economic challenges and the pre-eminence of a national logic of problem-solving. While supranational policies such as the European Stability Mechanism (ESM) and the failed refugee quota programme have been framed as expressions of institutionalised solidarity in the EU, important criticism uncovers their limited solidary outreach and entrenched conditionality. Consequently, the revival of the national interest as the ultimate mobilising factor for action and policy choice has been framed in terms of a crisis of European solidarity. This special issue approaches European solidarity in the context of economic and refugee crises from a multidisciplinary and multimethodological perspective and seeks to uncover both the opportunities and pitfalls of solidarity in the EU.

Is solidarity intrinsically linked to crisis situations? Are crises the terrain upon which solidarities flourish? The answer is not univocal, albeit several scholarly arguments point to this direction. Banting and Kymlicka (2017) define solidarity as "mutual acceptance, cooperation and mutual support in times of need". Baldwin (1990) associates it with "tools with which to reapportion and moderate the effects of national and manmade misfortune", while Stjernø (2011) refers to "interdependentness, inclusion and protection against social risks". In a recent publication, Gerhards et al. (2019) define solidarity as an action or institution through which A gives something to B to support/assist her. A slightly different angle is offered by Sangiovanni (2015), that defines solidarity as commitment, sharing and acting upon a goal

Irina Ciornei

iciornei@ibei.org

Malcolm G. Ross

m.g.ross@sussex.ac.uk

1 Barcelona Institute of International Studies, 08005 Barcelona, Spain

2 University of Sussex, Falmer, Brighton BN1 9QE, UK 
"in order to overcome an adversity". While historically, solidarity has been institutionalised to prevent future risks and adversities such as social marginalisation, unemployment, illness or natural disaster, recent EU history proves the opposite. Calls to solidarity have been made in order to redress crises rather than to prevent them, with the notable exception of cohesion policy which has been designed from the beginning to improve the economic situation of poorer European regions.

These definitions indicate that European solidarity is informed by a lively and polysemic concept of solidarity. To account for the complexity of solidarity manifestations in the EU context, this special issue starts from a minimal definition of solidarity that entails the sharing of goals and resources to prevent or redress situations of economic, social, political or environmental adversity. Who, how and under what conditions these resources are shared are dimensions that we clarify in the subsequent section. The contributors to the special issue do not offer a univocal answer but a plurality of modalities through which European actors can act in the spirit of solidarity.

The sharing of resources captures legal and institutional arrangements that promote solidarity on the one hand, and individual attitudes and behaviour on the other (Gerhards et al. 2019; Ross 2010; Ross in this issue). These latter may support or follow existing solidary laws and institutions, or may arise as bottom-up processes despite the absence of an institutional structure related to solidarity. The burgeoning research on welfare policies as expression of social solidarity show that solidarity attitudes and behaviours become enduring, self-sustaining and expanding when situated in an institutional context (Van Oorschot and Meuleman 2012). At the same time, social movements research illustrate that solidarity mobilizations can occur, expand but also wither independently of legal and institutional constraints (Della Porta 2018). The authors in this issue approach European solidarity from an institutional perspective that analyses policy responses of state and supranational political actors in the context of refugee crisis (Gurkan and Coman), a meso angle that looks at civil society organisations' solidary actions during the financial crisis (Eisele et al.), as well as individual support for solidarity measures in European countries and at the supranational level (Lengfeld and Kley; Ravazzini et al.). Theoretical contributions seek to underpin the normative principles that underlie a conception of solidarity beyond national borders (Ross; Wolthuis) as well as the building blocks of solidary action both at the individual and state level (Grimmel).

Boundedness and reciprocity are two important attributes that have been discussed in relation to solidarity and that are further examined in the EU context by the contributors of this volume (Grimmel; Ravazzini et al.). Implicit in most understandings of solidarity is its boundedness, i.e., that solidarity policies and practices are related to membership in a group or political community. This boundedness does not exclude solidarity at a global scale, with humanity writ large, but signals that the recipients of solidarity, as well as the actors that may be willing or are in a position to share goals, risks and resources with them, should be clearly defined (Hechter 1988; Lahusen \& Grasso 2018). In this case, solidarity is differentiated from the willingness to give, charity and universal humanitarianism (but see the Christian ethics on solidarity for a different approach). A subsequent attribute of solidarity that makes it sustainable as an institution and social practice in the long-run is 
reciprocity. Sangiovanni (2015) argues that reciprocity entails that "we ought to share the fate of other participants in the dimensions relevant to our joint action", similarly to Ross (2010) who describes mutuality as an integral part of solidarity. However, Banting and Kymlicka (2017) warn that this can become a double-edge sword. Reciprocity also paves the way to criteria on deservingness and conditionality, since only those that can "give back" or "share further" the goals, risks or burdens of solidarity arrangements are seen as legitimate recipients. Lengfeld and Kley's article is an original contribution to this topic by discussing how Europeans receive and support conditionality attached to solidarity policies in the EU. Indeed, the conditionality of solidarity is a repeated motif of solidarity at both theoretical and empirical levels in this special issue.

\section{Dimensions of analysis of European solidarity}

The theoretical complexity of the concept of solidarity may render the conception of European solidarity a Sisyphean task. At the same time, it constitutes a solid foundation for imagining solidarities that arise beyond the national-state level. EU membership is one institutional reality that can engender solidarity principles, policies and practices. These can be related to the decade-long territorial logic of redistribution that supports poorer regions in the EU, such as the Regional Policy. More recent instances of transnational solidarity, albeit profoundly contested, represent responses to the economic and refugee crises such as the ESM and the Temporary Relocation Scheme for Asylum-seekers. These policy initiatives as well as the interdependency of Member states in addressing social and economic risks generated a burgeoning academic interest regarding the possibility of solidarity arrangements in the EU. These arrangements encompass "vertical" solidarity, that arises among member states or between the EU and European citizens, as well as "horizontal" solidarity that develops among EU citizens with or without a pre-existing solidarity institutional framework (Ross 2020). Examples include work on social justice principles that should guide the institutional set-up of transnational solidarity (De Witte 2015; Ross 2010; Sangiovanni 2013), public support for fiscal solidarity at the EU level (Ciornei and Recchi 2017; Kuhn et al. 2017; Verhaegen 2017; Baute et al. 2019) and for asylum-seeker relocation schemes (Lahusen and Grasso 2018), meanings and framing of European solidarity in public discourses (Hobbach 2016; Wallaschek 2019) and the emergence of horizontal, grass-roots solidarity practices that mobilise to improve the lives of the vulnerable and excluded (Federico and Lahusen 2018; Lahusen and Grasso 2018).

Taking stock of the abovementioned normative and empirical scholarly endeavour, we argue that there are three dimensions that frame the study of solidarity at the transnational level. The first defines the trigger of European solidarity (also see Gerhards et al. 2019; Wallaschek 2019). The second dimension captures European solidarity outreach, and establishes who the solidarity actors are. Solidarity between member-states and among European citizens, respectively, are the main categories of actors mentioned by the recent literature (Baute et al. 2019; Ciornei and Recchi 2017; Ross 2010; Sangiovanni 2013), while regions are the main solidarity 
addressees of Regional Policy. The third dimension refers to the level of inquiry and locates transnational solidarity at the micro-, meso- and macro-levels (Lahusen and Grasso 2018). As in most social science research, the analytical distinction between these levels does not exclude communication and feedback mechanisms between them as we detail below.

The trigger of European solidarity refers to the particular situations (most likely of crisis or adversity) where the sharing of resources is called upon. On a similar vein, Wallasheck (2019) lists seven meanings of solidarity that range from economic and political to questions that challenge the legitimacy of solidarity in Europe, while Gerhards et al. (2019) talk about four domains, from fiscal to refugee solidarity. Yet, most of these classifications are constructed a posteriori based on past experiences. For this reason, we refrain from providing an ultimate list of the triggers of solidarity and the specific situations in which political actors and citizens will make appeal to it. This is due to the malleable and unforeseen adversity situations that may occur in the EU and global context, of which the 2020 pandemic is the most recent example.

For instance, European social solidarity can refer to sharing economic resources between regions, individuals and member states, respectively. This can be done through a permanent institutional mechanism that shares the benefits of EU membership and aims at reducing social, economic and political inequalities such as the various funds of Regional policy. Resource sharing can also presuppose a "punctuated" type of redistribution that is activated only when some member states, regions or individuals face crisis-like situations that significantly worsen their condition. This is the case of the present ESM, born during the sovereign debt crisis and also proposed as a solidarity instrument for the Covid-19 pandemic. The use of the ESM in order to address the pandemic shows how a crisis, whose domain is primarily healthcare and natural emergency, is addressed through instruments of fiscal solidarity. Additionally, European solidarity may also refer to sharing goals and joint action that are beyond economic redistribution and reduction of social inequalities. These can be related to democratic solidarity, i.e., the development of democratic norms and processes that increase the participation and representation of diverse social groups within the EU (Ross in this issue). Gurkan and Coman highlight the barriers that frustrated the fair allocation of refugees between member states in the summer of 2015 and the transformation of what could have been a solidarity scheme into a geostrategic outsourcing of the refugee crisis to Turkey.

Outreach refers to the recipients of European solidarity, which can be member states, citizens or regions. Solidarity schemes between member states received much attention in the literature and survey experimental research suggests that they are also preferred to other types of resource redistribution, i.e., from the EU to EU citizens (Vandenbroucke et al. 2018). The literature that places member states as the central actors of solidarity arrangements argues that solidarity should be aimed at "strengthening" constituent member states in the context of social, political and economic uncertainty and the uneven distribution of European integration outcomes (Sangiovanni 2013). In this sense, a minimalist form of member state solidarity should rely on an insurance against integration risks that is chosen under a thin veil of ignorance, in which states do not know their relative position (level 
of development, population size, welfare type, industrial production, etc.). On the contrary, a maximalist form of member state solidarity would seek to distribute the benefits and burdens associated with EU membership and would be similar to territorially redistributive logics found in most federal states today and at the level of regions through Regional Policy (Sangiovanni 2013). In this case, states would be entitled not only to compensations following from risk insurance schemes, but to redistributive mechanisms aimed at reducing social, political and economic inequalities between member-states.

When placing EU citizens at the heart of solidary arrangements, European solidarity encompasses laws and practices that involve goal or resource sharing among European citizens both vertically and horizontally (De Witte 2012; Ross 2010; Sangiovanni 2013). Some authors label this "transnational" solidarity in order to distinguish it from a state-centred type of solidarity (Sangiovanni 2013; Ciornei and Recchi 2017). Until recently, transnational solidarity has been applied in relation to freedom of movement and the non-discrimination principle that grants access to social rights to EU movers under equal conditions with the citizens of the residence state. As the practice has already confirmed and the normative arguments could easily envisage, the transnational solidarity manifest in the freedom of movement principle may enter in conflict with national solidarity and the redistributive logic tailored for its bounded national territory. Authors such as De Witte (2012) and Sangiovanni (2013) argue that there are some situations in which transnational solidarity may be restricted, i.e., impose limits of access to social rights for inactive EU movers.

A second wave of normative literature on transnational solidarity starts from the claim that European citizenship should become relevant to all EU citizens, movers and stayers alike (Eberl 2018; Granger 2016). Eberl (2018) argues that to overcome present shortcomings of European citizenship and solidarity, a supranational layer of social rights should be added to the already existing rights of free movement and anti-discrimination. Additionally, a social layer of European citizenship may also imply that transnational solidarity encompasses goal or resource sharing not only in relation to free movers, but among all EU citizens (Ross 2019; Vandenbroucke et al. 2017). In other words, a comprehensive conception of transnational solidarity mimics national solidarity schemes and concerns all European citizens, regardless of their free movement status. Less developed in the literature is a conception of democratic solidarity that allows for joint action and formation of transnational groups and alliances of European citizens and groups that share common social, political or economic goals (but see Ross in this issue).

European solidarity can be located at different levels of inquiry and created and sustained by a variety of social and political actors (Ross 2010; Lahusen and Grasso 2018). At the macro-structural level, solidarity designates principles, laws and policies that regulate goal and resource sharing between European member states and European citizens, respectively. Another focus on the macro-level of European solidarity is to analyse the field of actors engaged in its definition or enactment, such as national and European Parliaments or member state and commission officials (Carstensen and Schmidt 2018; Closa and Maatsch 2014; Gurkan and Coman in this issue). 
The meso-level of European solidarity has been insufficiently studied so far. An exception is the work of Lahusen and Grasso (2018) and Eisele et al. in this issue, who focus on civil society organisations' activities that are aimed at sharing material and non-material resources with other European organisations and citizens, respectively. These activities range from assistance related to the accommodation of refugees to financial and social aid to other Europeans in situations of social exclusion. It is important to note that these practices are not necessarily framed by supranational or national legislation in the field of European solidarity, but spring from individual and collective actors' initiatives. However, this type of solidarity is often conditional and 'soft' (European Commission 2018). In other words, the emergence of solidarity may depend upon multi-dimensional and context-specific factors that potentially limit its durability. Its soft character derives from often being outside formal structures and lack of enforceability, which also might work in favour of or against solidarity's resilience (Ross in this issue).

Lastly, the micro-level focus on solidarity encompasses both attitudes and practices of European citizens in relation to solidary principles and policies in the EU (Ciornei and Recchi 2017; Gerhards et al. 2019; Kuhn 2014). The attitudinal component of micro-level solidarity seeks to explain individual support for European solidarity principles but also for their more concrete policy formulations such as the Eurobonds, the ESM or The Temporary Relocation Scheme for Asylum-seekers. Other research also looks at solidarity practices with other people or organisations in the EU such as sharing money, time and other resources (Lahusen and Grasso 2018). These studies show that European solidarity is "alive and active" and that only a very small fraction of European citizenry clearly rejects any institutional mechanism that entail risk and resource sharing at the level of the Union (European Commission 2018).

However, there is virtually no linkage between the popular support for European solidarity and institutional principles and policies aimed at sharing goals, resources and risks on the territory of the EU. While an institutional form of solidarity that concerns member states and/or transnational solidarity is still in the making and will not necessarily be materialised in the foreseeable future, European solidarity as idea and as practice is much more widespread among the European populace. Consequently, the citizen-centred solidarity route may be the most pressing policy option to pursue given repeated inadequacies of the member-state focus.

\section{Content of the special issue}

Our special issue aims at elucidating some of the complexities of solidarity in the EU through the lens of sharing goals and resources among member states and their citizens. In particular, we marry theory and empirical evidence to demonstrate the forms and patterns of solidarity creation and their sustainability, especially in relation to particular policy areas and crisis events. We accordingly address questions related to social justice and social policy at the EU level, as well as state cooperation and fair allocation of refugees and asylum seekers. The papers offer a multidisciplinary perspective on solidarity in the EU covering the financial and subsequent 
sovereign bond crises of 2008-2013 (Ross; Eisele et al.; Lengfeld and Kley; Ravazzini et al.) and the refugee crisis of 2015 (Gurkan and Coman) while Grimmel and Wolthuis draw on both events. As regards outreach, the analyses focus both on EU citizens as solidarity recipients (Ross; Eisele et al., Duran-Mogollon and Paschou; Ravazzini et al.) and member states (Gurkan and Coman; Lengfeld and Kley).

An original contribution in relation to previous works published in the field is the focus on various levels of inquiry that range from member state level (Wolthuis; Grimmel; Gurkan and Coman) to the meso level of civil society organisations (Eisele et al.) and down to individual level focusing on behaviours and attitudes (Ross; Lengfeld and Kley; Ravazzini et al.). Additionally, the articles address general questions related to the opportunities and barriers of solidary actions and policies in the EU, beyond the specific empirical events they refer to. Wolthuis proposes an elegant solution to an ongoing debate in the normative literature regarding the distinction between solidarity and justice and offers theoretical tools in order to understand and properly inquire into real world situations that recall solidarity in the EU. Similarly, Grimmel offers a conceptual grid that help us grasp when individuals and states act in solidarity. M. Ross calls for a general mechanism that allows the translation of individual solidary actions in laws and policies in order to transform the "soft" potential of individual solidarity into an enduring institutional arrangement. This is an essential condition not only for a robust solidarity mechanism in the EU, but for its democratic survival as well. Eisele et al. reveal the weaknesses and strengths of civil society organisations when embarking in solidarity actions during the financial crisis, which can apply to a vast array of crisis events and solidarity appeals in the future. Gurkan and Coman show how a context that was previously framed as solidarity between member states is being redefined in terms of security and geopolitics due to the failure to reach an agreement. Future crises are likely to harbour similar dynamics, in which the inability of political actors to act in solidarity does not necessarily lead to policy failure, but to its reframing into a non-solidarity issue. Importantly, Lengfeld and Kley analyse citizen support for conditionality, one of the solidarity attributes that has been extensively debated during the economic crisis. Surprisingly, the same debate re-emerged regarding the use of the ESM for the Covid-19 pandemic, a fact which suggests that conditionality is a feature of European solidarity policies that is likely to stay on the Union's legislative landscape irrespective of the solidarity/crisis context that may emerge. Lastly, Ravazzini et al. address a long-standing puzzle in the literature on welfare solidarity by showing that attitudes towards redistribution and migration are not a zero sum game, but dimensions that can shape a variety of individual responses to national and supranational solidarity.

Drawing on recent empirical studies, Ross argues that European solidarity manifests itself as a first-order public good that legitimises policy interventions in the field. However, he considers that any search for a precise legal definition of solidarity is misguided when set against the myriad of attitudes and practices that have increasingly flourished among European citizens as responses to recent economic and social crises. Two consequences follow from this. The first is that solidarity can stand as a principle of interpretation of EU law that is "capable of shaping how functions and powers across the treaties are to be understood and exercised". The 
second concerns the nexus between European citizenship and solidarity, the key in Ross' view to a durable, resilient, 'horizontal' transnational solidarity. He points to the shortcomings of EU citizenship and concludes that solidarity cannot be enabled merely by adding an additional layer of social rights to existing free movement and non-discrimination principles. Rather, the EU should seize opportunities to develop and enhance processes and powers that allow for bottom-up expressions of solidarity attitudes and practices.

Grimmel's paper also proposes a practice based reading of the concept and seeks to find a common thread that ties the various uses of solidarity in day-to-day language. He argues that that the core elements that enact solidarity are voluntariness, selflessness and identification and positions himself against rational-choice explanations of solidarity based on self-interest. A central piece of solidarity conceived in this scheme, and that is also mentioned by Wolthuis in his paper, is the identification with others or with a shared idea. Identification confers solidarity a concrete objective that is necessary for action. The threefold understanding of solidarity proposed by the author sheds light on why it has been the grand absent during the economic and asylum-seeker crises. Grimmel considers that despite the rhetorical calls to solidarity, EU's "modus vivendi of integration that simply leaves little room for choices other than those that reflect narrowly defined self-interests and the pursuit of subjectively defined ends by rational actors" and that do not engender actions that are guided by voluntariness, selflessness and identification.

Wolthuis argues that the first step in defining European solidarity is to distinguish between solidarity and justice, especially since the two concepts have been interchangeably used by normative scholars of transnational solidarity. He considers that justice defines the basic rights through which cooperation under a system of law is possible, i.e., to assure a system of equal freedom for persons or states. Solidarity, instead, refers to cooperators' sharing of the benefits and burdens of cooperation. Thus, a person or a state may act in solidarity if it assists a co-operator, but a legal system is just if it allows a society of free and equal persons that can enter any cooperative agreement. With these distinctions in mind, Wolthuis concludes that the appeals to solidarity made by Italy and Greece during the refugee crisis are appropriate, since the burdens are heavier on some parts of co-operators than for others. Instead, the Greek debt crisis is not a crisis of solidarity, as the country received financial aid from other member states that maintained it on a floating line. Rather, the Greek crisis is one of justice, since the financial assistance conditions heavily limited this country's freedom of choice to design and execute its financial policy. Wolthuis' piece seems to suggest that conditionality should not be part of solidarity. This argument resonates with Grimmel's assertion on the selflessness of solidarity practices and also with Lengfeld and Kley's findings in this issue regarding the rather large rejection of austerity measured by European citizens.

Gurkan and Coman's paper shifts the focus onto European Union institutions and their framing of solidarity during the asylum-seeker crisis. The paper distinguishes between EU normative pouvoir, defined as the power of ideas and resorts to persuasion and argumentation that are promoted in a coherent and consistent way, and normative puissance, characterised by the promotion of principles through the offer or denial of material benefits. The framing of the asylum-seeker crisis in terms of 
member state solidarity showed the potential of ideational power to put at the forefront a European conception of solidarity. At the same time, EU's normative pouvoir to steer policies and practices of burden sharing showed its limitations. Eventually, the solution to the crisis has been mainly achieved through intergovernmental bargaining and primacy of the member state interest. On the contrary, the appeals made by the European Parliament to solidarity as a fundamental guiding value for state action, have been systematically downplayed and eventually replaced by a security focus discourse.

Eisele et al.'s paper makes an important contribution to the literature by showing the opportunities and limitations of solidarity practices at the meso level. While civil society organisations play a vital role in fostering social cohesion and in implementing solidarity initiatives, their success heavily relies on a series of organisational and contextual factors. The paper discusses solidarity practices in the fields of disability, migration and unemployment in Germany and Greece and observes that most of the organisations primarily focus on the local level, with very few being engaged in transnational activities. Material resources prove to be crucial for any type of solidary activities in the three fields mentioned and especially for a transnational span of organisational activity. It is the more professionalised and formalised organisations that are capable of supporting and sharing resources with the disabled, unemployed and migrants in other countries of the Union. This finding resonates with previous research on individual transnationalism and signals the unequal distribution of cross-border mobilities and collaboration. As the findings seem to suggest, European solidarity at the meso level is still a question of resources rather than willingness to share.

The paper by Lengfeld and Kley (2020) discusses the conditionality side of European solidarity by analysing public support for various types of austerity measures. Against the backdrop of increasing associations between conditionality and solidarity both in the literature and in public debates, the paper finds that the majority of citizens reject austerity measures, especially if they concern added tax, social spending cuts or raise of retirement age. Moreover, austerity measures are relatively equally rejected across social groups, entailing that there is at least a tacit consensus regarding the limits and conditions that can be asked in order to assist member states overburdened by social and financial crises. This finding ties in with the previous discussion of Ross and the grassroots support for European solidarity and suggests that the latter is not necessarily a social class or ideological issue, but a diffuse idea that is shared by most segments of the population regardless of their structural advantage. Lengfeld and Kley's findings seem to confirm that there is a general notion of solidarity that European citizens share, that the economically strongest shall strengthen the most vulnerable in society.

The paper of Ravazzini et al. (2020) discusses two core dimensions of national solidarity, support for the welfare state and openness to migrants who come to live in the country respectively, and how they are linked to transnational solidarity. This latter measures attitudes towards transnational solidarity, i.e., a hypothetical EUwide social benefit scheme that would guarantee a minimum standard of living for all poor people in the EU countries and that would be largely funded by the more affluent member states. Here too, the analysis shows that EU-wide solidarity with 
poor people appears rather strong. Regardless of the degree of support for national welfare or openness to migrants, the majority of European citizens are in favour of it. The authors conclude that "even when opposing the extension of full social rights to migrants in the national welfare system, most people do support the universal right to a minimum standard of living, presumably irrespective of the citizenship status".

Discussion of solidarity has never been more pertinent. Nor perhaps has its European future been more precarious. Is it to be confined to a response-and often a poor one-to crises or can it serve as a transnational policy foundation in Europe? It would be easy to be dismissive of solidarity, especially when the ruptures provoked by Covid-19 appear to have attracted delayed and predominantly financial responses at supranational or transnational levels. As the empirical papers in this collection have shown, solidarity measures are often highly conditional. These restraints on solidarity are produced by a political and legal framework that does not (yet) facilitate the evolution of a genuinely transnational space and relies instead on the primacy of national contestation and resources. There is accordingly a disconnect between the potential contributions of solidarity to a European society based on values of justice, equalities and social cohesion and the structural capacity to develop policies and interventions to achieve them. Hence the importance of the papers in this issue that address structural inhibitors across the macro, meso and micro levels. Moreover, the scope for solidarity is being squeezed by reframing discourse in terms of security threats requiring intergovernmental action. These barriers effectively hamstring solidarity in moving from crisis response to policy driver. Yet, repeatedly in these papers, there is empirical evidence of popular support for social interventions. The challenge becomes one of how to legitimise and activate solidarity within European decision-making processes. The future of solidarity will by a cypher for the future of Europe; all the more so if Europe continues to aspire to protect and improve the lives of its citizens.

\section{References}

Baldwin, P. 1990. The politics of social solidarity: Class bases of the European Welfare State, 18751975. Cambridge: Cambridge University Press.

Banting, K., and W. Kymlicka. 2017. The strains of Commitment: The political sources of solidarity in diverse societies. Oxford: Oxford University Press.

Baute, S., K. Abts, and B. Meuleman. 2019. Public support for European solidarity: Between Euroscepticism and EU agenda preferences? JCMS: Journal of Common Market Studies. 57: 535-550.

Carstensen, M.B., and V.A. Schmidt. 2018. Power and changing modes of governance in the euro crisis. Governance 31 (4): 609-624.

Ciornei, I., and E. Recchi. 2017. At the source of European solidarity: Assessing the effects of crossborder practices and political attitudes. JCMS: Journal of Common Market Studies 55 (3): 468-485. https://doi.org/10.1111/jcms.12507.

Closa, C., and A. Maatsch. 2014. In a spirit of solidarity? Justifying the European financial stability facility (EFSF) in national parliamentary debates. JCMS: Journal of Common Market Studies 52 (4): 826-842.

De Witte, F. 2012. Transnational solidarity and the mediation of conflicts of justice in Europe. European Law Journal 18 (5): 694-710.

De Witte, F. 2015. Justice in the EU: The emergence of transnational solidarity. Oxford: OUP. 
Della Porta, D. 2018. Solidarity mobilizations in the 'refugee crisis': Contentious moves. https://doi. org/10.1007/978-3-319-71752-4.

Eberl, O. 2018. 10. Transnational European civic solidarity. Reconsidering EU Citizenship: Contradictions and Constraints, 219.

European Commission. 2018. Solidarity in Europe. Alive and Active.

Federico, V., and C. Lahusen. 2018. Solidarity as a Public Virtue? Nomos Verlagsgesellschaft MbH.

Gerhards, J., H. Lengfeld, Z. Ignácz, F.K. Kley, and M. Priem. 2019. European solidarity in times of crisis: Insights from a thirteen-country survey. Abingdon: Routledge.

Granger, M.-P. 2016. Revisiting the foundation of European citizenship: Making it relevant to all European citizens.

Hechter, M. 1988. Principles of group solidarity. Berkeley: University of California Press.

Hobbach, R. 2016. Debating European burden-sharing. National debates in the aftermath of European crises. ECPR General Conference, Prague, Czech Republic.

Kuhn, T. 2014. Experiencing European integration: Transnational lives and European identity. Oxford: Oxford University Press.

Kuhn, T., H. Solaz, and E.J. van Elsas. 2017. Practising what you preach: How cosmopolitanism promotes willingness to redistribute across the European Union. Journal of European Public Policy. https://doi.org/10.1080/13501763.2017.1370005.

Lahusen, C., and M. Grasso. 2018. Solidarity in Europe-European solidarity: An introduction. In Solidarity in Europe, 1-18. Cham: Palgrave Macmillan. https://doi.org/10.1007/978-3-319-73335-7_1.

Ross, M. 2010. Solidarity-A new constitutional paradigm for the EU? In Promoting solidarity in the European Union, 24-45. Oxford: Oxford University Press.

Ross, M. 2019. Chapter IV. In Borgmann-Prebil, Y., Ross, M. and Ciornei, I. (Eds.), The transformation of citizenship: A policy review. European Commission.

Sangiovanni, A. 2013. Solidarity in the European Union. Oxford Journal of Legal Studies 33 (2): 213-241.

Sangiovanni, A. 2015. Solidarity as joint action. Journal of Applied Philosophy 32 (4): 340-359.

Stjern $\varnothing$, S. 2011. The idea of solidarity in Europe. European Journal of Social Law, 3.

Van Oorschot, W., and Meuleman, B. 2012. Welfare performance and welfare support. Contested Welfare States: Welfare Attitudes in Europe and Beyond, 25.

Vandenbroucke, F., C. Barnard, and G. De Baere. 2017. A European social union after the crisis. Cambridge: Cambridge University Press.

Vandenbroucke, F., B. Burgoon, T. Kuhn, F. Nicoli, S. Sacchi, D. van der Duin, and S. Hegewald. 2018. Risk sharing when unemployment hits: how policy design influences citizen support for European unemployment risk sharing (EURS) (AISSR Policy Report 1). AISSR.

Verhaegen, S. 2017. What to expect from European identity? Explaining support for solidarity in times of crisis. Comparative European Politics. https://doi.org/10.1057/s41295-017-0106-x.

Wallaschek, S. 2019. The discursive construction of solidarity: Analysing public claims in Europe's Migration crisis. Political Studies, 0032321719831585.

Publisher's Note Springer Nature remains neutral with regard to jurisdictional claims in published maps and institutional affiliations. 